\title{
Game Prototype for Daily English Practice
}

\author{
An Approach Design by using a Puzzle, Riddle and Adventure Scenario
}

\author{
Chaidir Ali \\ Computer Science Program \\ Bina Nusantara University \\ Jakarta, Indonesia
}

\author{
Ronald Thiodorus \\ Computer Science Program \\ Bina Nusantara University \\ Jakarta, Indonesia
}

\author{
Ida Bagus Kerthyayana Manuaba \\ Computer Science Program \\ Bina Nusantara University \\ Jakarta, Indonesia
}

\begin{abstract}
English language is one of many languages which has been used to communicate around the world. In era of global competition, where most people do interaction borderless, language plays an important role as communication tool. However, many people in the countries where English is a second language, where they rarely speak English in daily life, it could cause lack of confidence which is leading them to be left behind in global competition. In forestall this issue, it is important for people to practice English since early stages of education and use it in daily activity. This paper proposes an alternative solution to improve confidence in learning English in fun way. By creating educational game that can be played in daily activity, it is expected could help people, especially young generation, to improve confidence in practicing English.
\end{abstract}

\section{Keywords-Educational Game, Puzzle Game, Android}

\section{INTRODUCTION}

English language is a common language that used for communication among people from all over the world. In some countries, for example in Indonesia, English language becomes important and it is also one of compulsory subjects that are included in standard national curriculum. However, since English is not a primary language, it is hardly used in daily conversation, which caused most of the Indonesian might have less experiences and confidence in using it for communication. This information is also accordance to Hetrakul [1], which stated that in most countries when English is not their first language, the students tend to avoid using the language.

In addition, based on Astuti [2] study on The Gap between English Competence \& Performance, found that Indonesian people have difficulties in using English for communications. She showed that $43 \%$ of the respondents feel shy and $53 \%$ of the them feel not confident or nervous. These number shows that most of Indonesian people avoiding speaking English on their daily life conversations. In addition, the culture and environment in Indonesia also do not support for people to communicate in English. If this condition continues, it might become a problem for Indonesian people to compete in Global competition in upcoming years.

Taking on any new language, including English, need serious commitment, motivation, and a dogged willingness to learn. Besides, utilizing a right tool could also improve the learning result, it means by using appropriate media/tool could accelerate the learning progress. In learning language, instead of doing it in traditional way or in another name known as passive learning method (reading, listening or speaking based on text book), people could learn better when they do the learning process as a group of activities. Based on diagram of learning model [2], It shows that people generally remember up to $90 \%$ of what they do compare to the other learning method. Here, using a media/tool, for example games, can be more effective compare to just read the book or to listen news from radio.

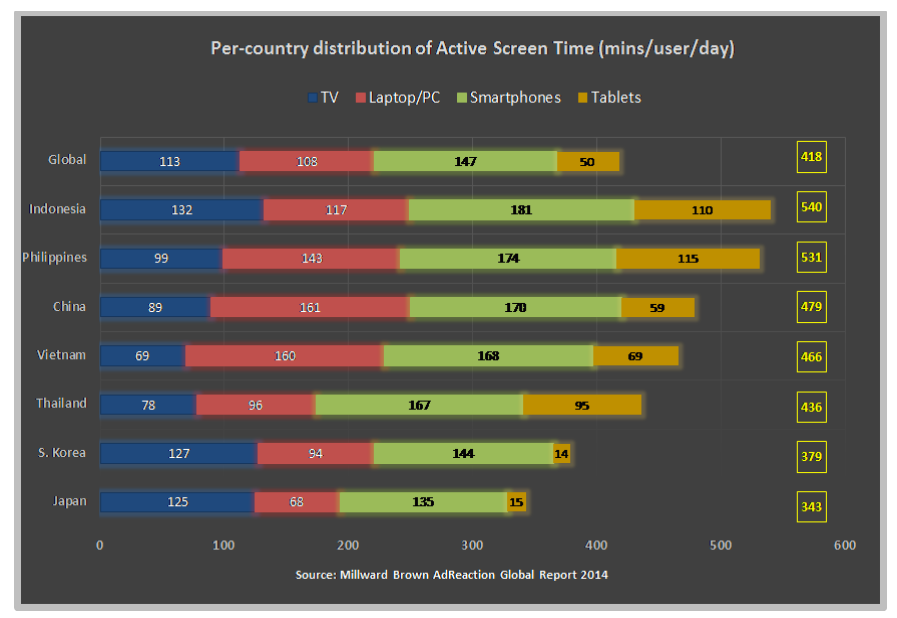

Fig. 1. Data survey of active screen time from 8 different countries. [3]

As part of the advanced technology, most people in Indonesia are very familiar with smartphones. Based on recent report by global media research firm [3]. It shows that people in Indonesia use their gadget more than anyone else in the world. Based on Fig. 1, the data shows that Indonesia has the highest number of using smartphones compare to other devices. This means that the smartphone plays important role in people daily life.

Based on another data from Nielsen website [4], their survey on smartphones users, based on a number group of ages, found that smartphone owners ages 25-44 use the greatest number of apps per month (29 apps, on average), but 18-24year-olds spend the most time on them ( 37 hours, 6 minutes). Time spent does decrease with age, but apps are clearly playing a big role in the lives of all smartphone users. In addition, they 
survey also shows that smartphone users spend the most time on search, social apps and entertainment (includes games, movie, music). Here, there is very huge potential to develop a game application using a smartphone as an alternative media to deliver learning material.

Based on the data survey mentioned previously, group age from 18 to 24 years old are spending their most daily time in using smartphones. It means, this group is the most suitable users that be a target on developing an educational game application. Hopefully with this educational game application, it could help people to practice using English for daily communication. Using this application, Indonesian people are expecting can play and learn English language using their smartphone in daily basis.

There are a lot of games that have been created for education purpose. Most of the games are also available on mobile and on website. Moreover, most of the existing applications can be accessed anywhere and everywhere, through internet connection. However, the current games that available in market mostly focused only on teaching for children (not teen) or English module exam/practicing. In addition, there is also very limited application that suitable for English daily practice, or utilizing media game as a learning platform before in Indonesia. Hence, it caused that the contents and stories are very limited and simple, and the gameplay is only designed to match with children needs.

In this paper, we will describe the development and usage of mobile application with android operating system, with target user is high school student. For prototype purpose, an educational game with puzzle riddle concept will be utilized to deliver English language closer to student. In addition, it also has feature that allow further developer to expand it and feature to run offline. Android OS is used since this OS is the most affordable smartphone in the market [6]. Especially in Indonesia, android smartphone is the most popular smartphone. With game education in android app, we hope we can provide an affordable media, which is fun and entertain to be used to practice English language for daily activities.

\section{GAME FOR EDUCATION}

\section{A. Definition of Game}

Game, according to Merriam-Webster [16], is "a physical or mental activity or contest that has rules". While according to Oxford dictionaries [17], game is "a form of competitive activity played according to rules". Wolfgang [18] described that to call an activity a game, it must have fulfilled some basic criteria. Those criteria are common experience, equality, freedom, activity, and diving into the world of game.

The "common experience" means players who play the game is having same experiences without any consideration to their personal trait such as gender and race. "Equality" means that every player who play the game have equal standing in it so every player has the same chance to win the game. "Freedom" means players decide to play the game without any enforcement to play it. "Activity" means that game enforce people to become active when playing the game whether it is thinking, moving, or others. "Diving into the game" means players who play the game is immersed themselves in the game and affected by rules of the game rather than rules in real life.

Other than the criteria mentioned previously, Wolfgang [18] also stated there are four other factors that need to be fulfilled for the activity to be called a game. Those criteria are game rules, goal, chance, and competition. Game rules is the boundary of the game itself and served as a base for the game to be played correctly. Goal is a requirement set for a game and players must achieve it as a condition to end the game. Chance is a factor that make game equal for every player as it is unpredictable. Competition is a way to make the game more enjoyable for players because they are competing for winning in the game. This factor is considered important for a game as it draw emotions from players that cannot be achieved by another activity.

In addition, there is also study about the benefits of playing games by Isabela Granic [7]. It discussed about how video games increase people skills especially children and adolescents in several domains which are cognitive, motivational, emotional and social. According Granic's research, an action game turns out increasing wide range of cognitive skills, in this case is attention skill. She found that people who almost never played video games before, and then were assigned to play some video game for a period of times, showed that they have faster and more accurate attention allocation. Hence, game can also be used as tools for education and improving some skills.

\section{B. Educational Game}

Educational game is a game that designed not for entertainment only, but also designed for learning purpose [19]. In applying a learning process, this type of game need to provide a user's experience that they can adopted from real-life situations. Although the game is mainly for learning purpose, the gameplay for educational game need to support the learning purpose to enable players to feel the experience.

Education games can be categorized into two form, simple game and complex education games. Simple education game is mainly used for training basic skills of the players, such as memorization or simple questions-answers games. In this type of game is usually utilizing puzzle-themed game where players must interact with in-game objects to solve the puzzle. In the sides, complex education game is normally used for training skills where players do not usually encounter in their daily life. For example, is a simulation game where players become a pilot of a helicopter in war zone or a pilot of a commercial airplane.

\section{Puzzle Game}

There are two characteristics of puzzle game mention in Rabi's article [8]. First, he stated that "fun where puzzle game is form of play", and second, he also stated, "puzzle has correct answer". These two statements mean that puzzle game need to provide a form of play that guide the player to interact with the game environment to find clues that will guide them into the right answer. However, the mechanism should be challenging but less complex so the player will keep engage on the situation where they feel curious and to keep the play's 
going. More detail about good puzzle designed is described in the following paragraphs:

The first principle, the goal of puzzle game need to be easy to understand by the player, therefore a player will get interested to play the puzzle game at the outset. For example, given a hint or instruction to the player. Lose interest will happen if player did not know what they supposed to do in with the puzzle in game.

The second principle, puzzle game needs to be easy to get started. After the goal of puzzle game is clear, it is needed to be easy to get started when solving the puzzle, for example give a simple puzzle to solve at early level. A puzzle game that hard to solve in the beginning will make player use trialand- error approach to solve it and worst scenario is when player completely abandon the puzzle.

The third principle, puzzle game need to give sense of progress to the player. A riddle games simply given to player and expected and answer while puzzle game give sense of getting closer to the solution. For example, player is given several clues during the game then use-collected clue to solve the main goal of the game.

Fourth principle, puzzle game needs to give solvable sense to the player. Giving feedback to player about their progress is an example of providing solvable sense. Players might have a feeling that they waste their time or get frustration if the puzzle seems not solvable; therefore, convincing the player that the puzzle is solvable is important.

Fifth principle, puzzle game needs to increase its difficulty gradually. Series of actions or small steps towards final solution can be added to increase puzzle game difficulties. In increasing the difficulties of puzzle game, can be assigned when player is required to answer several questions, that questions can be answered in any order then each question give hint or clue to the player if it get solved.

Sixth principle, puzzle game needs to give player time to rest, it means there might be a moment where player stuck and cannot solve the puzzle given, hence it is good thing to give another puzzle or task as alternative. It is not a good thing if player leave the game because they got stuck in one puzzle.

Seventh principle, make a pyramid structure of puzzle game. It means that puzzle game has series of small puzzle that lead to large puzzle by give some clue. A small goal toward lager goal also can be combined to make puzzle game have pyramid structure.

Eighth principle, when designing a puzzle game, the game needs to give some hints to the player, it is better to give player hint to solve given puzzle rather than they cannot solve the puzzle and give up or search outside the game.

Ninth principle, the puzzle game needs to give the answer to the player, for example at the end of the game, player cannot answer the last question or solve the last puzzle but the game still give the real answer of the question or puzzle given. By giving the answer to the player, the joy did not come from solving the puzzle rather comes from "Aha" feeling when player finally figure out the answer. Player might feel satisfy to find the answer even though they not solved the puzzle because when player tried so hard but not successful, to rush they will want to find the answer not matter what.

The last principle, puzzle game needs to have a perceptual shift. It means when people see a shape or word that can look like different things, for example the optical illusion depending on how people look at it. In puzzle game, perceptual shift is when the player can solve the puzzle they will get excited but if they cannot solve the puzzle, they will not get anything, just see it unsolved puzzle. Puzzle game that has perceptual shifts did not offer the third and the fifth principle which are progress and increase difficulty because player is might to spent a lot of time to solved a puzzle until find the true answer of the puzzle given.

\section{Develop Confidence to Practice English}

Xu-Lihua [9] mentioned that one of the psychological problems to communicate using English is losing face cultural where students are afraid to be embarrassed if they make mistake in language learning process. That problem causes student to have lack of self-confidence to communicate using English. There are several points that require to increase student self-confidence which are, careful planning, skillful motivation, different techniques, patient instruction, relaxed atmosphere and visual stimuli.

There are two principles to planning a good lesson, (1) Variety where student is involved in different activities and (2) Flexibility, means use different techniques not only fixated to one methodology. A detailed plan about teaching technique, speaking activities and material are also needed to be prepared beforehand to produce good lesson planning.

Motivation for student to learn English will be increased if the goals are attractive. Many students feel unmotivated to learn English because it is part of their curriculum at school. Hence, an easier and attractive goal needs to be set for students to increase their motivation to learn English.

A constantly change of activities is needed in speaking practice. There is no topic that should overworked, it is better to stop whilst rather than continue it to bitter end. Teachers should not depend too much on text books while taught English language in class even it is a good one because student might feel boring and find the routine less motivating. For example, Teacher can use storytelling method where teacher can have a role-play and start it with small groups. If the method and topic are interesting for student, it can be lengthened but if not it should change to different method and topic instead.

One of virtues that greatly needed by teacher is patience. Students develop their skill trough practicing and making mistakes during learning process, where teachers needs great patience to correct those mistakes. At advanced stage, student who inexperienced as a speaker may feel discomfort to face their listener, their voice became quivers and their mind goes 
blank. In those situation, teacher can help them by being friendly, helpful and not criticizing their effort. Stopping a student while they make some errors as a speaker numerous time can lead to risk of silencing the student itself. Hence even though errors and mistake are unavoidable, the teacher should never lose hope for their student.

A relaxed atmosphere is needed to increase student confidence. A classroom atmosphere where student afraid to make mistake and ridicule by their classmate can lead to psychological obstacle. Hence students are preferring to be silence in classroom with those atmospheres. To overcome those problems, the teacher could create a relaxed atmosphere for example with games, songs and puzzles because people will become more talkative if supported by relaxed atmosphere, psychologically. With relaxed atmosphere, student will able to develop their oral skill with confidence as well as enjoy themselves while studying English language.

Pictures, cartoons, slides, maps and tapes are several items that can be categories as visual element which one of another source for oral English practice [9]. With those visual element, the student interest and attention will be aroused. Moreover, a live language situation can be brought to the class room that make many meaningful learning, for example pictures used to start a discussion. In addition, it is important to choose the topics to stimulate students to speak English [10]. When student found that the topics is interesting then they will be motivated to discuss those topics. There are several topics that student may interested in as show in figure bellow:

Dimitrios [11] categorized traditional method as a teachercentered. it means that the method put responsible on teacher to teach the knowledge to their student. Teacher centered also means that any material and student assessment are determine by the teacher itself to be teach to the students in various way.

\section{E. Definition of Gameplay}

Carlo [20] stated that gameplay is the way that players interacting with the game world, what players can do in game, how the game world reacted to player's actions and what players experienced while following the game rules.

Carlo also mention that game mechanics and the balance element are some requirements to design a good gameplay [20]. Game mechanics are method that allow interaction happening with the game state [21] while the balance element is how the games are designed to have a balance between game mechanics learning process and application process [20].

Goals and components of the game are also important to build a good gameplay [22]. Determine how the goal can be achieving or how many paths available to achieve the goal is one of the way to design good goals of the game. The example of components of the game are the character, the weapon or the vehicle and it is important to ensure that each of game component have serve some purposes.

\section{System ANALYsis AND Design}

\section{A. Existing Problem and Solution}

There are several approaches to increase English language skill for senior high school students besides learning from school, for example: (1) joining English language course, (2) watching English video and listening English radio, (3) selftaught like reading books or newspaper in English. However, they seem not effective to make student speak English language. Practical education system in Indonesia still more concerned about score rather than mastering the subject itself, hence students are unable to use their skill in practice [23]. Moreover, in English language course, the learning method is similar to school, where student is monotonous taught by the teacher. Learning method like that spend $60 \%$ of session, the other $30 \%$ are spent for quiz or exam and $10 \%$ for the others, hence student does not have much time to learn English Language communicatively [24].

There are several Existing Solution for above problem that can be used to improve English skills:

- Joining private courses seems to be the most favorite and common solution for student to gain additional knowledge outside school. Commonly, they provide different materials for example science subject and social subject. Some of them also only focus in English Language for example English First and Wall Street. In Indonesia, there are about 13.446 private class courses spread all around city and about $45.51 \%$ from 1.348 .565 participants who join the courses are from senior high school [25].

- English Educational Testing is a free application provided by English Educational Testing Service that provided lots of topics that covers listening and reading skill in English Language. The application is easy to use with total one hundred lessons separate into four that in each lesson consist of audio content, question and transcript content [26].

- Learn English by Conversation is an application provide by SCD Group that cover listening, grammar and speaking English skill with add-on English dictionary. There are various lessons provide by this application, for example conversations from BBC learning and English at work. An audio, transcript and vocabulary list are included in each lesson as a feature provide by the application [27].

\section{B. Proposed Solution}

Although there are several approaches to improve English Language skill of Indonesian high school student. It is still not sufficient. Difficulties to speak English are still found among student because their low self-confidence and less experiences. Hence, by utilizing current technology and game education approach, it is expected can become alternative options to improve English daily practice. 


\section{Design OF The PROTOTYPe IMPLEMENTATION}

Besides applying the tenth principles in developing educational puzzle game in mobile application platform, it is expected we could develop an educational game that has purposes for media practicing in learning English for daily usage, the game need to be designed to cover four English skills, reading, listening, reading and writing.

\section{A. Gameplay Design}

For this initial prototype game designed, a puzzle game story has been developed to match the high school student level as the target audience. Two dimensions' game environment and character were created. The main story is about soling a riddle puzzle. The story begins when the character in game, named $L a w u$, want to find his friend, named Andi, that is missing in action during group project assignment. A magician is willing to help Lawu with requirement which is needed to answer all the questions given and each corrected answer will give piece of information regarding Andi whereabouts.

There are ten questions in total that player needs to answer during the gameplay. Begin with an initial question at the beginning of the game, followed by eight sub-questions and one final question at the end of the game. The cycles of the game are: (1) player is required to answer the initial question. (2) after answering initial question player will start looking clues for the next three questions in library. Player can move the character to leave the library to answer the next questions without option to turning back. (3) every three questions, the player will start looking for another clue regarding the three next questions, that will be asked when the game reach the final question which is the question tenth. In the end of the game-stage the last question will show hints about Andi whereabouts according to how many corrected answer from previous questions. The last question will determine whether player solved the puzzle and win the game or not.

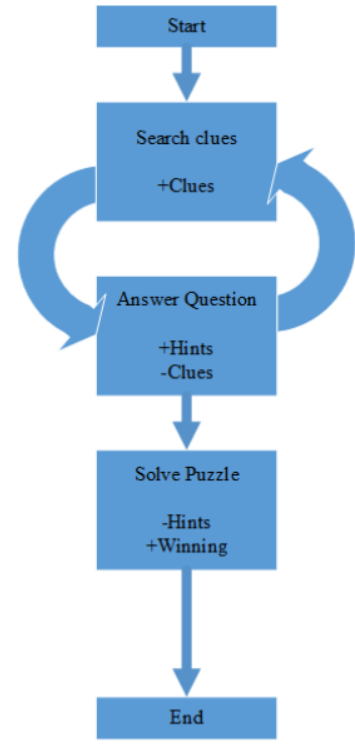

Fig. 2. Screenshot of Game Puzzle User Interface
According to Fig. 2, There are three major parts in this game core loop: (1) Search clues, (2) Answer questions and (3) solve puzzle. In search clues part, player is gathering as much as possible clues that will be used to answer the question. When player answers the question, they used the clues that they have collected before, so they can answer correctly and will gain more hints to solve the puzzle. The process of search clue and answer the questions are repeatedly happened, the more player got hints with answer the question correctly, the winning probability also increased since the collected hints will be used to solve the puzzle.

During the gameplay, player will be provided with reading materials and interactive audio to search for clues. This activity will allow player to practice their reading and listening skills. In addition, a mini-game to arrange a word puzzle also embedded in this game to variate different environment that could keep the player to play the game. Besides input from the screen, this puzzle game will also use voice recognition features from Android Speech Recognizer Plugin as one of the input of the games. This voice input is used to answer the questions given. This feature will encourage player to conduct speaking practice while playing the games.

These use cases focus on player actors when they enter the room to search clues. Player can do several actions while he/she in room: (1) Move the character, player can move the player around horizontally using either right or left buttons. (2) Interact with object, player can interact with various objects in room to search the clues needed. (3) Player also can read books and (4) listen audio file in game room, but those two action are dependent whether player has interacted with object or not. (5) Receive instruction, the player can get instruction regarding the location of the clue. (6) Player also can move the barrel with same way with character movement when player enter mission stage to collect fallen word. (7) Last, player can choose to exit the game room that to move to question scene.

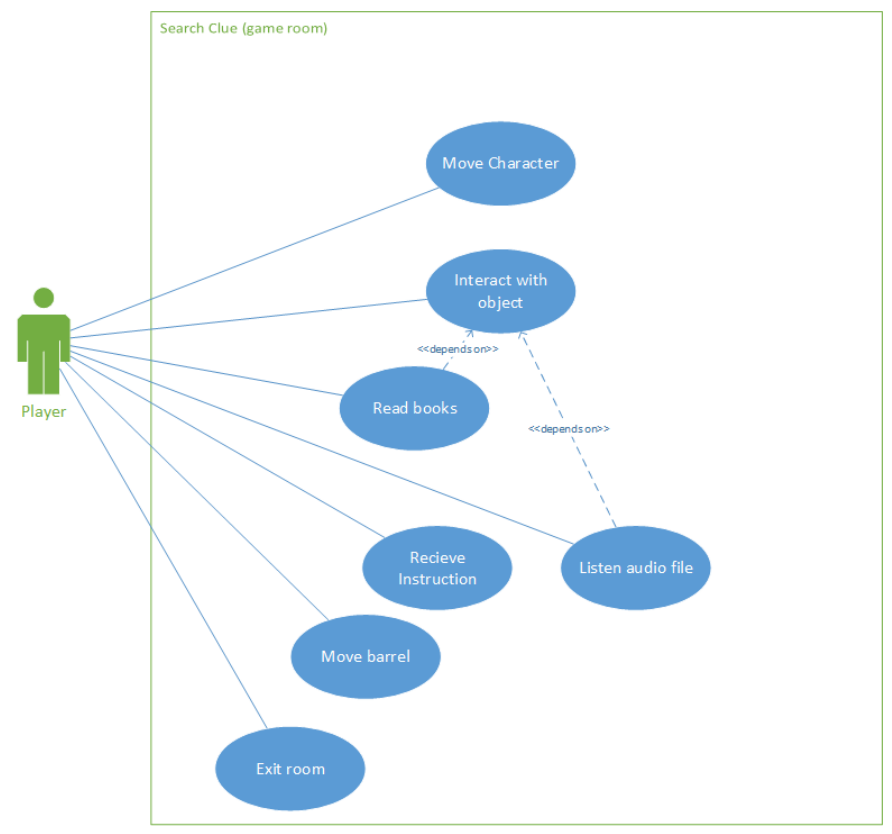

Fig. 3. Search Clue. 


\section{B. Technology Stacks}

This game prototype is expected can run effectively on Android OS platform. Besides, it is also expected to be expanded and be ran offline for further development. Here a good database designed is required to address this purpose.

\section{- Unity $3 D$}

Unity3D was used to develop the proposed solution. It is because it offers full features to create games for free. Unity3D also has an asset store that will be useful on building the user interface for the game. In addition, Unity3D also support Android Speech Recognizer Plugin that can be used to receive data form for Android (through smartphone's microphone). Another reason is because Unity3D offers portability to many platforms so the game can be ported to any platforms Unity supports.

\section{- Android Speech Recognizer Plugin}

Android is used as the operating system because the high number of users in Indonesia. Many affordable mobile devices have android as their operating system and because of that, many Indonesian high school students use mobile devices with android operating systems. For that reason, the game will be designed to be able to run in mobile devices with android operating system.

\section{- SQLite}

All the list of questions answers, and clues for the gameplay will be saved into database. The decision to use a database to save these three variables is to allow this puzzle game to be expanded. For further usage, more variant of questions can be easy to add and delete which make the game suitable for long-term usage. Design of the table can be seen on Fig. 3.

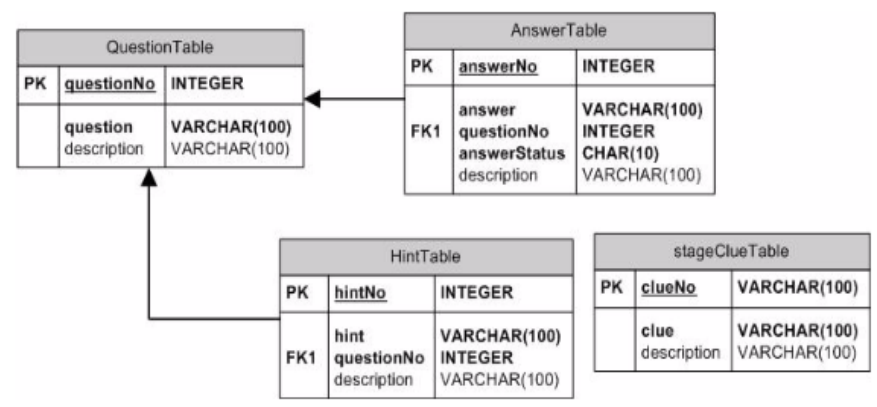

Fig. 4. Database designed.

SQLite is used as the database system for this proposed solution because it can be built using code. As Unity3D does not have a database function, a database must be created from scratch. To build the database, it will use $\mathrm{C \#}$ programming language which Unity supports and has libraries for SQLite functions.

\section{Prototype Interfaces}

Images below are sample screenshot of the puzzle games:

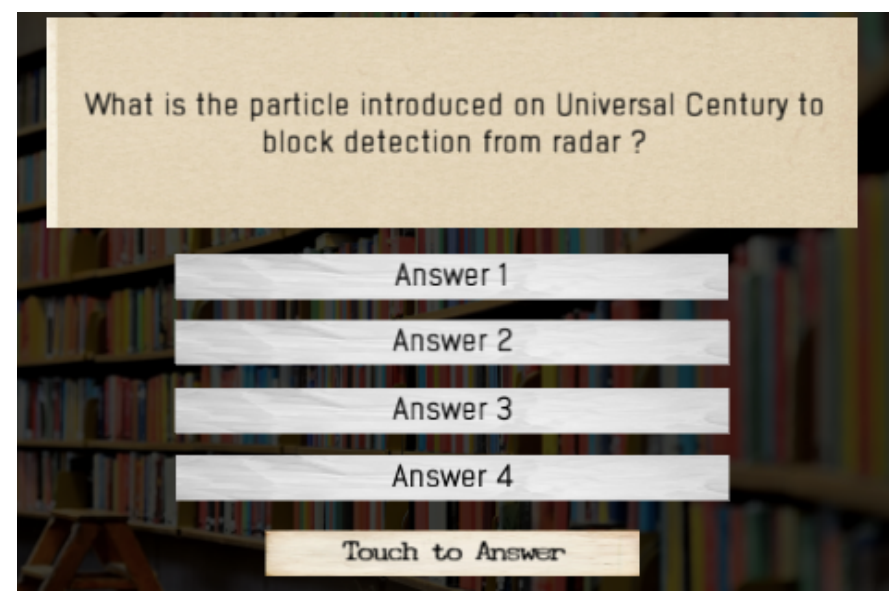

Fig. 5. Screenshot of Question Scene, where player need to use voice to read the correct answer. They need to press the "Touch to Answer" button to activate the voice recognition.

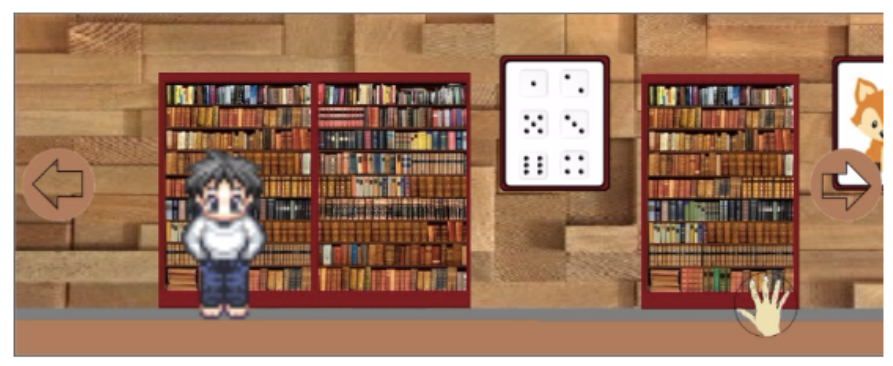

Fig. 6. Screenshot of Game Puzzle User Interface, player can move the avatar by pressing the arrow to interact with the object and search for clues.

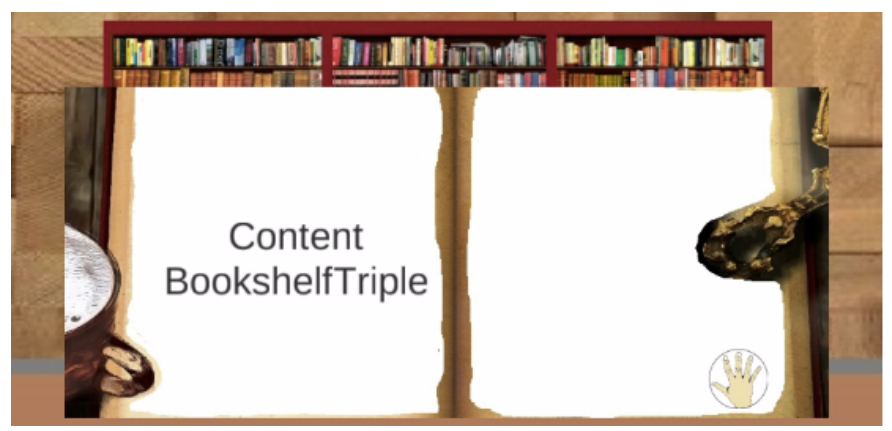

Fig. 7. Screenshot of Book Content To Display Reading Material, clues can be revealed by reading the story provided from these scene.

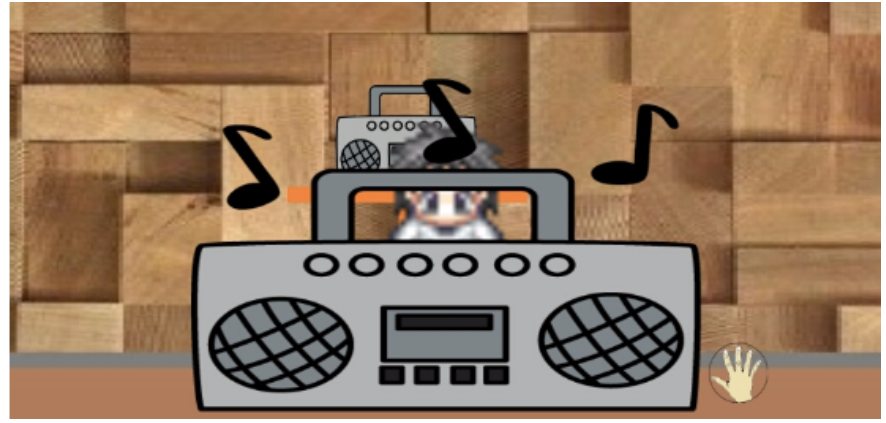

Fig. 8. Screenshot of Radio as a source of interactive audio for listening practice. 


\section{PRE - IMPLEMENTATION}

The objective of this experiment was to develop an educational game that can be used as media to practice English language. To make sure the application work effectively for high school students in daily life as target users, we conduct a user testing using this prototype. Before conducting play testing, this game prototype has been tested using Application Unit Testing method to make sure all the features of the game are working properly.

\section{A. Participants}

Table 1 below is the characteristics of the participants that participate for this user testing.

TABLE I

PARTICIPANTS CHARACTERISTICS

\begin{tabular}{|c|c|}
\hline Characteristics & Frequency (\%) \\
\hline $\begin{array}{cl}\text { 1. Gender } \\
\qquad \quad \text { Male } \\
\bullet \quad \text { Female }\end{array}$ & $\begin{array}{l}60 \% \\
40 \%\end{array}$ \\
\hline 2. Ranging ages & Range: $16-19$ years old \\
\hline 3. Background & $\begin{array}{l}\text { High School Students with } \\
\text { basic English required }\end{array}$ \\
\hline
\end{tabular}

\section{B. Testing Setup and Procedure}

\section{- Hardware Specification}

In general, any device that use android as operating system with version 2.3 or higher is compatible with the software. However, in this project, this software was only tested using Asus ZenFone 4s (A450CG) with specification in detail:

- Chipset: Intel Atom Z2520

- CPU: Dual Core 1.2 GHz

- RAM: $1 \mathrm{~GB}$

- Resolution: 480 x 854 pixels

- OS: Android 4.4.2

- Multi-touch: YES

- Sensors: Accelerometer, proximity, compass, sound

\section{- Testing Procedure}

The play testing was conducted individually by each participant. There were preconditions that need to be fulfilled before conducting the game play. First, the participants were required to calibrate the voice recognition feature to work with their own voice. Second, all participants were required to read all the instructions before they start to play the game. In this testing, participants can control the character of the game, however the movement was limited, such as only for entering a room, for moving around and for interacting with various objects to find the clues. Three different level of difficulties are applied into this game. This feature was applied to make the game more interactive and challenging.

In this play testing, the game scenario is divided into 3 stages. The first stage is started when the game is begun. Here, a participant started by answer the first question. This question is followed by the first riddle sentence that need to be answered by the participant. Then, participant is required to move a character in the game to explore the first room and do interactions with the objects to find a clue. The first form of the clue is a text. After participant successfully found the first clue, the participant is required to answer question two, three and four. There is no information whether the participant answers are correct or wrong, any correct answer will be rewarded for a clue in the end of question nine.

Continue with the game, answering question two to four is also indication that the participant entering stage two with higher level of difficulty. the second riddle statement appeared after completing question four. Then all participant need to continue to move around to find the second clue. The form of second clue is coming from audio object. After the participant successfully found the second clue, they were required to continue to answer question five to seven. Obviously, these questions have higher level of difficulty compare to the previous three questions.

Entering the final stage, the participants are required to find the latest clue by following instruction from audio object and text (combinations). After they complete the challenges, the participants need to answer question eight and nine. In all previous answering process, the participant will not get any information whether they have answered right or wrong. Before the participants answering the final question (the riddle answer), they received additional clues as the reward based on how many they can answer the question two to nine correctly. The collected clues will help the participant to answer the riddle. The detail scenario of the game and the stages boundaries can be seen in the Fig. 9.

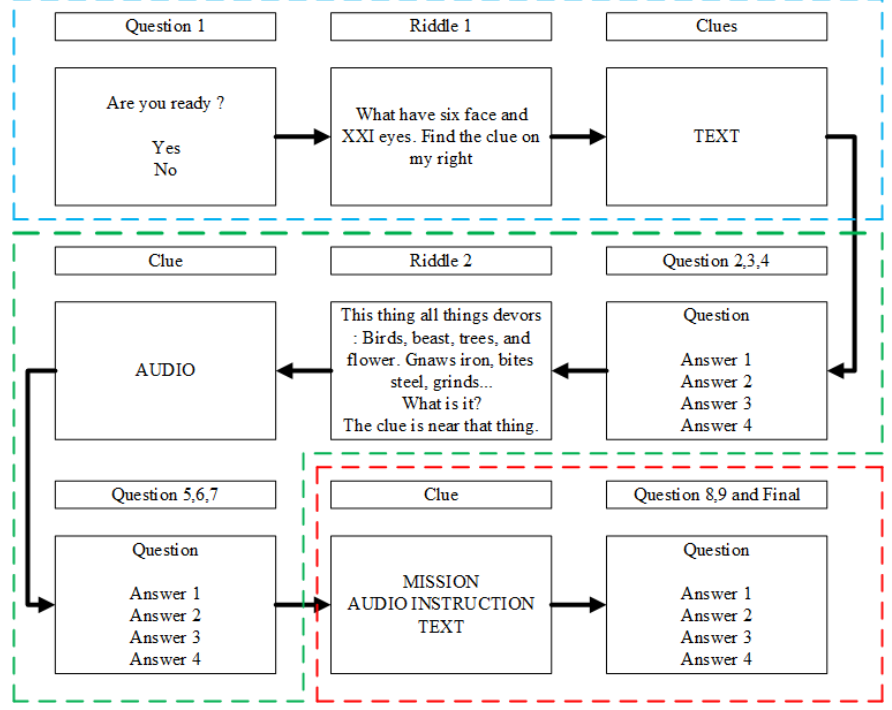

Fig. 9. Scenario of the game

Finish conducting the play testing, participants were required to answer a questionnaire. This questionnaire was included 5 Likert scale questions related to game performance and several open questions to get feedback from the participants. 


\section{RESULT AND DISCUSSION}

This game prototype has been successfully passed Application Unit Testing with full mark for each feature/function tested. This test is important to make sure the following play testing could run properly.

Based on the play testing, $100 \%$ of the participants can complete the game. $80 \%$ of the participants could collect more than five clues. However only $20 \%$ participants could collect all the clues provided. Unfortunately, we could not do further analysis on time performance since we missed to record total completion time for all participant.

In addition, from data questionnaire, we found that all participant is familiar with android smartphone. By using paired T-test analysis with one tile distribution, we test the different mean of familiarity of the smartphones and performance in collecting clues and found that the t-value is equal to $8.74 \times 10^{-5}$. This number means there is strong correlation between the familiarity of the smartphones and performance in collecting clues.

By using similar paired T-test, this play testing also successfully shows that the different mean is very small between gender and participant performance in collecting clues, with t-values is equal to $9.15 \times 10^{-5}$. However, it still not enough to conclude that this finding could represent the sample populations since the number of participants is very limited and homogeneous.

Another data from questionnaire shows that more than $80 \%$ of participants agree that they like to play this game through the phone. More than $80 \%$ are also strongly agree that this media can help to practice their English skills. However only $40 \%$ said strongly agree to keep playing this game repeatedly. With this result we can say that this game successfully engages the participant to play a game and make them unconsciously practice their English skill. However, the limited scenarios of the riddle game and questions variant could make them stop to play the game after a couple attempt. Provide more riddles and question, and make them more dynamic will create a game that can be fun to play repeatedly.

In addition, $60 \%$ participants agree and 40\% strongly agree that this game could be an alternative media for them to practice English. And $40 \%$ of them said strongly agree and $60 \%$ agree that this game will possibly increase their confidence in using Speaking and Listening English. And the last one, they also said the material and the themes of the game is interesting.

Based on open questions part of the questionnaire, the feedback from the participants are about design interfaces. There are still improvements required on (1) the button to move right and left needs to have more noticeable color and (2) character move.

\section{CONCLUSION AND RECOMMENDATION}

\section{A. Conclusion}

Though English language has been taught from elementary school but, it is hardly use outside the school especially in country where English is not the first language. Since English language is rarely use outside school, student might have less experiences and lack of confidence in using English to communication in real life situation. Currently there are several attempts to increase student's English language skill but, additional effort to solve those problem is important to be added. One important thing to do is gain the student interest and it can be done by using video games as intermediary to deliver the English language itself.

As the we found that there is a connection between learning process and video games, we decide to build a video games that have education purposes on it as a group project. The video games have several main parts which are gameplay, voice recognition, user interface and database. In this project, the we responsible in developing the gameplay. A puzzle and riddle category has been added to this video games with purposes make it more challenging and fun gameplay for high school students as target market of the video games. Several literature reviews have been conducted that we used trough development process and discovered the benefit of playing video games, how to increase student confidence, what engine that will be used to develop the game and which platform that the game will be run.

Lot of times is needed when develop the game application start with game design until the game is playable. During those process, we find several constraints like unavailability required asset, debug problem on android device and integration process with another team member project.

After the game tested by application unit testing method and ready to play testing, a user testing has been conducted to find out several aspects from the game and evaluate it. Even though the game is a prototype, but all the function, the game loop and game flow has worked properly. From the user responses, the result is mostly positive such as by playing this game can increase player confidence to speak English, even though it need many improvements in some areas such as the game topics and materials.

To conclude, the game application successfully delivered all the requirement in the research scope and this paper might be good references for future works. We hope this application can be one way to help to make people in Indonesia become well educated.

\section{B. Recommendation}

The game application has run and work properly but, there are several improvements that can be done for future development:

- Based on participant's comments, the application need to have improvement in the animation character and the modeling.

- Improve features function that will work on both android and $\mathrm{PC}$.

- Work with 2D artist that have good understanding about asset. 


\section{REFERENCES}

[1] K. Hetrakul, "The Second Language," 5 May 1995. [Online]. Available: http://eserver.org/courses/spring95/76100g/KavinHetrakul.html. [Accessed 9 March 2016].

[2] A. Case, "UE Using English," 2008. [Online]. Available: http://www.usingenglish.com/articles/why-your-students-haveproblems-with-listening-comprehension.html. [Accessed 1 May 2016].

[3] K. Reddy, "WiseStep," 7 April 2015. [Online]. Available: http://content.wisestep.com/top-ways-to-improve-oralcommunication- skills-in-english/. [Accessed 1 May 2016].

[4] I. Wurinanda, "kampus," 4 Febuary 2016. [Online]. Available: http://news.okezone.com/read/2016/02/17/65/1314663/inikelemahan-orang-indonesia-belajar-bahasa-inggris. [Accessed 13 March 2016].

[5] A. Kohn, "Educational Leadership," The Case Against Grades, p. 2, 28 November 2013.

[6] S. Hill, "digitaltrends," 26 December 2015. [Online]. Available: http://www.digitaltrends.com/mobile/best-smartphone-os/. [Accessed 2016 March 13].

[7] Isabela Granic, Adam Lobel, and Rutger C. M. E. Engels, "The Benefits of Playing Video Games," pp. 1-13, 2013.

[8] R. Afram, Puzzle Design in Adventure Games, p. 32, 2013.

[9] X. Lihua, "Developing Student Confidence in Speaking English," TELS Reporter, pp. 26-31.

[10] "Secondary English," in Building your students' confidence to speak English, TESS-India, p. 4.

[11] B. Dimitrios, S. Labros, K. Nikolaos, K. Maria, K. Athanasios, "Traditional Teaching Method VS Teaching Through the Application," p. 29, 2013.

[12] "CIRTL Network," [Online]. http://www.cirtl.net/node/2570. [Accessed 01 June 2016].

[13] "BBC Active," [Online]. http://www.bbcactive.com/BBCActiveIdeasandResources/Innov ativetea chingmethodsvsthetraditionaluni.aspx. [Accessed 01 June 2016].

[14] J. Brodkin, "insights dice," 3 June 2013. [Online]. Available: http://insights.dice.com/2013/06/03/how-unity3d-become-agame- development-beast/. [Accessed 30 March 2016].

[15] M. Sheridan, "Unity News," 15 March 2016. [Online]. Available: https://unity3d.com/company/public- relations/news/unity-launches-two- new-versions-unitycollaborate-feature-and-unity. [Accessed 30 March 2016].

[16] S. Brachmann, "Ipwatchdog," 26 November 2014. [Online]. Available: http://www.ipwatchdog.com/2014/11/26/a-briefhistory-of- googles-android-operating-system $/ \mathrm{id}=52285 /$. [Accessed 31 March 2016].

[17] C. Gray, "Librarypoint," [Online]. Available: http://www.librarypoint.org/android_history. [Accessed 31 March 2016].

[18] K. Carlon, "Androidpit," 17 March 2016. [Online]. Available: https://www.androidpit.com/android-m-release-date-newsfeatures- name. [Accessed 31 March 2016].

[19] "SDLC Agile Model," [Online]. Available: http://www.tutorialspoint.com/sdlc/sdlc_agile_model.htm. [Accessed 01 May 2016].

[20] C. Fabricatore, "Gameplay and Game Mechanics Design: A Key to Quality In Video Games," Gameplay and Game Mechanics Design, p. 18.

[21] M. Sicart, "Defining Game Mechanics," [Online]. Available: http://gamestudies.org/0802/articles/sicart. [Accessed 0 July 2016].

[22] "5 Basic Elements of Game Design," Make School, [Online]. Available: https://www.makeschool.com/gamernews/298/5basic- elements-of-game-design. [Accessed 7 July 2016].

[23] J Leimena. Negarawan Sejati Dan Politisi Berhati Nurani. Jakarta: PT BPK Gunung Mulia.

[24] K.H,"Peningkatan Komunikasi Aktif Bahasa Inggris Melalui Totor Sebaya dan Diskusi Pada Siswa Kelas X SMA Negri 1 Kartasura," p. 36, 2010.

[25] "infokursus," Direktorat Pembinaan Kursus \& Pelatihan, 2016. [Online]. Available: http://www.infokursus.net/stat.php. [Accessed 29 March 2016].

[26] E. E. T. Service, "English Listening Test," English Educational Testing Service, 6 January 2016. [Online]. Available: https://play.google.com/store/apps/details?id=vn.magik.englishl a\&hl=en. [Accessed 28 March 2016].

[27] S.Group. "Learn English By Conversation". SCD Group,15March2016. [Online]. Available: https://play.google.com/store/apps/details?id=vn.scdgroup.bbcle arninge English. [Accessed 28 March 2016]. 